\title{
DHPLC analysis as a platform for molecular diagnosis of congenital disorders of glycosylation (CDG)
}

\author{
Els Schollen ${ }^{1}$, Kevin Martens ${ }^{1}$, Elke Geuzens ${ }^{1}$ and Gert Matthijs ${ }^{*, 1}$ \\ ${ }^{1}$ Center for Human Genetics, University of Leuven, Leuven, Belgium
}

Since 1997, the molecular basis of six different types of Congenital Disorders of Glycosylation with a defect in the synthesis of $\mathrm{N}$-glycans (CDG-I) has been identified. To assure an efficient molecular diagnosis of the six genes involved in these types, we established a denaturing high-pressure liquid chromatography (DHPLC) screening procedure. Primers were designed and conditions were optimised for the analysis of each exon of the PMM2, MPI, ALG6, ALG3, DPM1 and MPDU1 genes. Forty previously described PMM2 mutations were tested to evaluate the method. All of them could be detected. Hence, the sensitivity of the technique is virtually $100 \%$. Screening of 17 novel cases with a tentative, clinical diagnosis of CDG-la identified mutations on both alleles in 14 of them, thereby confirming the diagnosis. Six of these mutations were not previously reported (G15E, G42R, Y64C, E93A, G214S and D223N). Sequencing of the complete coding sequence of $P M M 2$ in the remaining three patients did not reveal mutations, corroborating the good performance of the DHPLC method. A similar DHPLC approach was also applied to CDG-Ib, CDG-Ic, CDG-Id, CDG-le and CDG-If samples. New mutations were identified in MPI (Y129C) and ALG6 (G227E). All results were confirmed by sequencing. We conclude that the DHPLC platform is a sensitive and efficient method for the rapid analysis of disease genes with a limited number of exons.

European Journal of Human Genetics (2002) 10, 643-648. doi:10.1038/sj.ejhg.5200858

Keywords: congenital disorder of glycosylation; mutation analysis; glycosylation defects; PMM2; DHPLC; MPI

\section{Introduction}

In less than 5 years, the molecular defects of six types of congenital disorders of glycosylation, group I (CDG-I) have been identified (for review ${ }^{1,2}$ ). In CDG-I, patients have a deficiency in one of the enzymes involved in the synthesis or transfer of the dolichol-linked oligosaccharide precursor. ${ }^{1}$ This results in a typical pattern of transferrin isoelectric focusing. The clinical diversity of CDG is remarkable, even within each group. ${ }^{2,3}$ CDG-Ia patients with a deficiency of phosphomannomutase (PMM) are the most frequent and have been extensively studied at the clinical, biochemical and molecular level (for instance ${ }^{4-6}$ ). The phenotype ranges from a severe multi-system disease including cerebellar hypoplasia, hypotonia, ataxia, psychomotor retardation,

${ }^{*}$ Correspondence: G Matthijs; Center for Human Genetics, U.Z. Gasthuisberg, Herestraat 49, O\&N6, B-3000 Leuven, Belgium; Tel: +32 163460 70; Fax: +32 16346060 ;

E-mail: gert.matthijs@uz.kuleuven.ac.be

Received 15 February 2002; revised 24 May 2002; accepted 6 June 2002 failure to thrive, and liver disease to a very mild phenotype with only mild mental retardation. ${ }^{3,7}$ The second most frequent type, CDG-Ic, has a clinical presentation that is close to, but typically milder than CDG-Ia. ${ }^{8-10}$ CDG-Ib has a different presentation, as it does not generally include neurological problems. ${ }^{11-13}$ The other types are rare. ${ }^{14-18}$

Confirmation of the clinical diagnosis relies on enzymatic studies and/or lipid-linked oligosaccharide (LLO) analysis followed by molecular analysis of the gene. ${ }^{2}$ Most of the mutations described today are scattered over the corresponding genes. It seems that no hotspots exist be it that some mutations are more frequent, due to founder effects. $^{5,6}$ For PMM2, more than 50 different mutations have been described. ${ }^{6}$ Only six of them have been found in more than 10 families. In MPI and ALG6, 13 and 6 different mutations have been described in 10 and 9 patients respectively. ${ }^{4,10,13,19,20}$ A survey of all published mutations in CDG-I can be found at http://www.kuleuven.ac.be/ $\mathrm{med} / \mathrm{cdg} /$. 
The variety of mutations implicates that the whole coding region of the gene has to be examined for routine screening. In order to offer a fast screening of the six known genes and in anticipation of the identification of other genes involved in CDG-I, we introduced DHPLC analysis. DHPLC is a new screening method that allows the detection of single base variations based on the difference in melting profiles of hetero- and homoduplexes under controlled denaturing conditions. The method is automated and allows rapid screening of numerous samples in a 96-well format. The sensitivity has been shown to be $100 \%$ in several studies (for review see ${ }^{21}$ ) and the platform has been implemented for screening of many disorders.

We designed primers and optimised the DHPLC procedure for all the exons of the PMM2, MPI, ALG6, ALG3, DPM1 and MPDU1 genes. The method has been used for routine diagnosis of 21 patients with tentative diagnosis of CDG-I and was found very convenient and sensitive.

\section{Methods \\ Patients}

Patients with known PMM2 mutations have previously been described. $^{7,22}$ From 17 patients with a tentative diagnosis of CDG-Ia, nine had a phosphomannomutase deficiency in fibroblasts or leukocytes. From eight enzymatic data were not available but they all showed a type I transferrin IEF pattern and a clinical picture suggestive for CDG-Ia. Two patients were referred to our laboratory for molecular confirmation of CDG-Ib. In two novel patients with CDGIc, the clinical presentation, the transferrin IEF pattern and the accumulation of dolichol-Man ${ }_{9} \mathrm{GlcNAc}_{2}$, as shown by the analysis of lipid-linked oligosaccharides (LLO), ${ }^{8}$ were suggestive for CDG-Ic.

Total genomic DNA was extracted from blood, fibroblast cultures or EBV-transformed lymphoblast cultures by standard laboratory procedures.

\section{PCR amplification}

Primers have been designed for amplification of all individual exons of the six genes (PMM2, MPI, ALG6, ALG3, $D P M 1$ and MPDU1), including at least $30 \mathrm{bp}$ of intronic flanking region. Exons 4 and 5 of DPM1 and exons 2 and 3 of MPDU1 were amplified in one fragment. Primers were designed with 'Primer3' (http://www-genome.wi.mit.edu/ cgi-bin/primer/primer3_www.cgi) with a typical length of $20 \mathrm{bp}$. Primer sequences are available on request.

PCR reactions were done in $100 \mu \mathrm{l}$ with $1 \times$ PCR buffer (Roche, Mijdrecht, The Netherlands) with 25 pmol of each primer, $0.2 \mathrm{~mm}$ dNTP's, $2 \mathrm{U}$ Taq polymerase and $200 \mathrm{ng}$ genomic DNA. All PCR mixes were amplified with the same touch down program: $95^{\circ} \mathrm{C}, 5 \mathrm{~min}, 10$ cycles of $\left(95^{\circ} \mathrm{C}\right.$ for $30 \mathrm{~s}, 65^{\circ} \mathrm{C}$ (minus $1^{\circ} \mathrm{C} /$ cycle) for $30 \mathrm{~s}, 72^{\circ} \mathrm{C}$ for $30 \mathrm{~s}$ ), 25 cycles of $\left(95^{\circ} \mathrm{C}\right.$ for $30 \mathrm{~s}, 55^{\circ} \mathrm{C}$ for $30 \mathrm{~s}, 72^{\circ} \mathrm{C}$ for $\left.30 \mathrm{~s}\right)$ and a final extension at $72^{\circ} \mathrm{C}$ for $5 \mathrm{~min}$.
PCR products were analysed on agarose and pooled prior to heteroduplex formation $\left(95^{\circ} \mathrm{C}\right.$ for $2 \mathrm{~min}$, slow cooling to $45^{\circ} \mathrm{C}$ followed by $20 \mathrm{~min}$ at $45^{\circ} \mathrm{C}$ ). Amplicons of the same fragments from maximum three patients were pooled in approximately equal concentrations, as estimated from the intensity of the bands on agarose after EtBr staining.

\section{DHPLC conditions}

DHPLC analysis was performed on the Transgenomic Wave system as prescribed by the manufacturers (Transgenomic, Cheshire, UK). Ten $\mu$ l of pooled (see above) crude PCR product (approximately $10 \mathrm{ng} / \mu \mathrm{l}$ ) was loaded on a DNASep Column (Transgenomic). DNA was eluted from the column by a linear acetonitrile gradient in $0.1 \mathrm{~mm}$ triethylamine acetate (TEAA) buffer at a constant flow rate of $0.9 \mathrm{ml} /$ min. The gradient was formed by mixing buffer A (0.1 mM TEAA) and buffer B (0.1 mM TEAA, 25\% v/v acetonitrile). The temperature of the oven for optimal heteroduplex separation at partial DNA denaturation was deduced from melting profiles of the DNA sequence, obtained with the Wavemaker 4.0 software (Transgenomic). Elution patterns of (pooled) patient samples were compared with those of normal control samples. Precise conditions (column temperature, gradient conditions) are available on request.

\section{Identification of mutations by direct sequencing}

Samples showing abnormal DHPLC profiles were reanalysed to confirm and identify the mutation. Fifty $\mu \mathrm{l}$ PCR product was purified on Microcon 100 columns (Millipore, Etten-Leur, the Netherlands). Direct sequencing was performed with the Big Dye Terminator cycle sequencing kit (Applied Biosystems, Foster City, CA, USA) essentially as described by the manufacturer. Samples were sequenced on an ABI 310 or ABI 3100 (Applied Biosystems) and analysed using the sequence analysis software of Applied Biosystems.

\section{Results}

Evaluation of the system

More than 50 different PMM2 mutations have been described in CDG-Ia patients and samples were available in our laboratory for most of these. Therefore, this gene was the perfect tool to optimise and evaluate the DHPLC analysis system. DNA samples of patients, known to be heterozygous for 40 different mutations were amplified and analysed at the proposed temperatures (Table 1). Figure $1 \mathrm{~A}$ gives an example of a melting profile, ie of exon 8 , as generated by the Wavemaker software. The position of the eight mutated nucleotides in exon 8, included in this study, is indicated and so are the exon/intron boundaries. The elution profiles of a normal sample and of the eight mutant fragments at two column temperatures are shown in Figure 1B. In general, for 38 of the 40 mutations in this series, an elution profile clearly distinct from the control sample was 
Table 1 List of PMM2 mutations used for evaluation of the DHPLC system

\begin{tabular}{|c|c|c|}
\hline Exon & Base change & AA-change \\
\hline \multirow[t]{2}{*}{1} & $26 \mathrm{G}>\mathrm{A}$ & C9Y \\
\hline & $43 \mathrm{G}>\mathrm{C}$ & G15R \\
\hline 2 & $\begin{array}{c}95 \mathrm{TA}>\mathrm{GC} \\
131 \mathrm{~T}>\mathrm{C}\end{array}$ & $\begin{array}{l}\text { L32R } \\
\text { V44A }\end{array}$ \\
\hline 3 & $\begin{array}{c}193 \mathrm{G}>\mathrm{T} \\
205 \mathrm{C}>\mathrm{T} \\
\text { IVS } 3+2 \mathrm{~T}>\mathrm{C}\end{array}$ & $\begin{array}{c}\text { D65Y } \\
\text { P69S } \\
\text { splice variant }\end{array}$ \\
\hline 4 & $\begin{array}{c}303 \mathrm{C}>\mathrm{G} \\
317 \mathrm{~A}>\mathrm{G} \\
434 \mathrm{C}>\mathrm{T} \\
324-325 \text { del } \mathrm{G} \\
338 \mathrm{C}>\mathrm{T}\end{array}$ & $\begin{array}{c}\text { N101K } \\
\text { Y106C } \\
\text { A108V } \\
\text { frameshift } \\
\text { P113L }\end{array}$ \\
\hline 5 & $\begin{array}{c}357 \mathrm{C}>\mathrm{A} \\
359 \mathrm{~T}>\mathrm{C} \\
367 \mathrm{C}>\mathrm{T} \\
368 \mathrm{G}>\mathrm{A} \\
385 \mathrm{G}>\mathrm{A} \\
391 \mathrm{C}>\mathrm{G} \\
395 \mathrm{~T}>\mathrm{C} \\
395 \mathrm{~T}>\mathrm{A} \\
389-390 \text { del } \mathrm{C} \\
422 \mathrm{G}>\mathrm{A}\end{array}$ & $\begin{array}{c}\text { F119L } \\
\text { I120T } \\
\text { R123X } \\
\text { R123Q } \\
\text { V129M } \\
\text { P131A } \\
\text { I132T } \\
\text { I132N } \\
\text { frameshift } \\
\text { R141H }\end{array}$ \\
\hline 6 & 451-454 del GAAA & frameshift \\
\hline & $\begin{array}{l}452 \mathrm{~A}>\mathrm{G} \\
458 \mathrm{~T}>\mathrm{C} \\
470 \mathrm{~T}>\mathrm{C} \\
484 \mathrm{C}>\mathrm{T} \\
523 \mathrm{G}>\mathrm{C}\end{array}$ & $\begin{array}{l}\text { E151G } \\
\text { I153T } \\
\text { F157S } \\
\text { R162W } \\
\text { G175R }\end{array}$ \\
\hline 7 & $\begin{array}{l}563 A>C \\
590 A>C \\
623 G>C\end{array}$ & $\begin{array}{l}\text { D188G } \\
\text { E197A } \\
\text { G208A }\end{array}$ \\
\hline 8 & $\begin{array}{l}647 \mathrm{~A}>\mathrm{T} \\
653 \mathrm{~A}>\mathrm{T} \\
677 \mathrm{C}>\mathrm{G} \\
682 \mathrm{G}>\mathrm{T} \\
691 \mathrm{G}>\mathrm{A} \\
697 \mathrm{G}>A \\
710 \mathrm{C}>\mathrm{G} \\
710 \mathrm{C}>\mathrm{T} \\
722 \mathrm{G}>\mathrm{C}\end{array}$ & $\begin{array}{l}\text { N216I } \\
\text { H218L } \\
\text { T226S } \\
\text { G228C } \\
\text { V231M } \\
\text { A233T } \\
\text { T237R } \\
\text { T237M } \\
\text { C241S }\end{array}$ \\
\hline
\end{tabular}

The mutations in the shaded boxes have not been published before.

obtained. The heteroduplexes with mutations V44A (exon 2) and I132T (exon 5) could not be visually separated from the wild type homoduplexes at the theoretical temperatures, calculated by Wavemaker 4.0. Only when the chromatograms of the mutant and normal control samples were overlaid, a difference could be detected (Figure 2 and results not shown). A screening at all temperatures from $50^{\circ} \mathrm{C}$ (non denaturing conditions) to $62^{\circ} \mathrm{C}$ (complete denaturation) did not result in a better separation.

I132T is caused by a $\mathrm{T}>\mathrm{C}$ transition at position 395 in exon 5. A $\mathrm{T}>\mathrm{A}$ transversion at the same position causes I132N. To check whether the specific base change itself affected the chromatogram, the elution profiles of fragments with I132T and with I132N were compared. The resolution of the peaks was much better for the fragment with the $\mathrm{T}>\mathrm{A}$ transition than with the $\mathrm{T}>\mathrm{C}$ transversion at the same position (Figure 2), indicating that the precise nucleotide substitution strongly affects the melting characteristics of heteroduplexes, as expected.

\section{Screening of PMM2 gene in CDG-Ia patients}

The optimised conditions were used for routine screening of PMM2 in 17 patients with a possible diagnosis of CDGIa. The eight exons were amplified and PCR products were pooled prior to heteroduplex formation and analysis on DHPLC. Pooling warrants the identification of mutations in samples from patients that are homozygous for a particular mutation. Positive DHPLC patterns were further analysed by direct sequencing to confirm and identify the underlying mutation. Mutations were found on both alleles in 14 patients, confirming the diagnosis of CDG-Ia. Six mutations were not reported before: G15E, G42R, Y64C, E93A, G214S and D223N. Two other mutations (24delC, F206S) were published ${ }^{6}$ before but not included in our test series. For the three other patients, the negative DHPLC results were confirmed by direct sequencing of the complete coding sequence and the flanking intronic sequences. The definitive diagnosis is pending in these cases.

\section{Screening of MPI, ALG3, ALG6, DPM1 and MPDU1}

The same strategy was followed for the other five genes. PCR primers and conditions were optimised for all exons. Known mutations were used to test the DHPLC conditions (column temperature and gradient). Table 3 lists the mutations in the different genes that were tested. All of them could easily be detected, although some problems have been encountered with MPI. The flanking regions of the several exons of MPI are very polymorphic and therefore obliterate the DHPLC read-outs. New primers were designed to circumvent this problem.

In the last year two patients with CDG-Ib and two with CDG-Ic were referred to our centre for confirmation of the clinical diagnosis. All exons were analysed on DHPLC after amplification and heteroduplex formation. Fragments with an aberrant elution profile were sequenced. Two mutations were found and hence the diagnosis was confirmed for both CDG-Ic patients and for one of the CDG-Ib cases. Sequencing of the eight exons of MPI in the other CDG-Ib patient confirmed the negative DHPLC results. For both MPI and ALG6, a new mutation was identified: Y129C in $M P I$ and G227E in ALG6.

Most recently, no novel patients have been diagnosed with CDG-Ib, Ic, Id, Ie and If in our service, and therefore, no diagnostic analyses were run for the corresponding genes. Still, the system is ready for use on patient material.

\section{Discussion}

Generally speaking, these results show that the analysis temperatures and gradient conditions calculated by the 


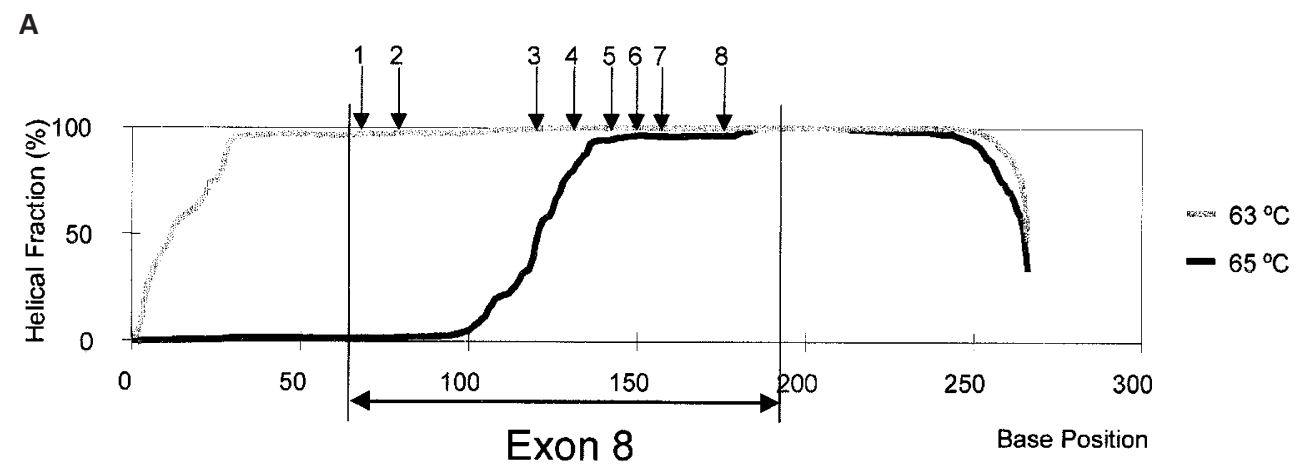

B

Mutation

Normal controle

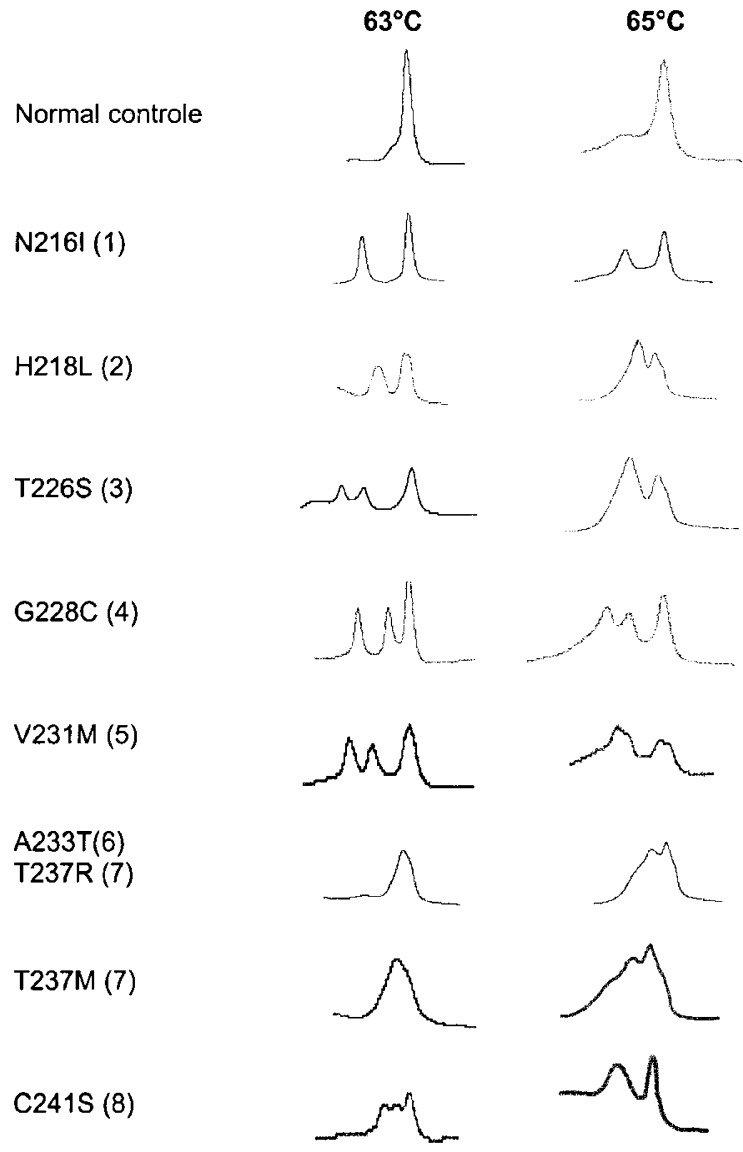

Figure 1 (A) Melting curve of exon 8 and flanking sequences of PMM2 as calculated by Wavemaker software 4.0. The position of eight mutations is indicated by the numbers corresponding to the numbers in (B). The grey curve gives the helical fraction (\%) of the fragment at $63^{\circ} \mathrm{C}$, the black curve at $65^{\circ} \mathrm{C}$. (B) Elution profiles of amplicons of exon 8 . A normal control sample and samples from eight patients heterozygous for the indicated mutation and were amplified as described. Heteroduplexes were allowed to form and the products were analysed by DHPLC under standard conditions and column temperatures of $63^{\circ} \mathrm{C}$ or $65^{\circ} \mathrm{C}$. The numbers between brackets correspond to the numbers indicated in (A). Sample six contains both A233T and T237R on one allele.

Wavemaker 4.0 software allow the detection of a variety of mutations. The DHPLC sensitivity in this experiment was virtually $100 \%$. This fits nicely with recent data, eg from a blinded comparative study on mutations in the BRCA1 gene, in which (only) DHLPC correctly identified each of 58 distinct mutations. ${ }^{23}$ Almost no optimisation is necessary when the PCR primers are designed properly and PCR conditions are set-up according to the manufacturers 
Table 2 List of genotypes of novel CDG-la patients analysed by DHPLC

\begin{tabular}{lccccc}
\hline \multicolumn{5}{c}{ Patient No mutations } \\
& Base 1 & AA1 & Base 2 & AA2 & $\begin{array}{c}\text { Country } \\
\text { of origin }\end{array}$ \\
\hline 1 & $44 \mathrm{G}>\mathrm{A}$ & $\mathrm{G} 15 \mathrm{E}^{* *}$ & $422 \mathrm{G}>\mathrm{A}$ & $\mathrm{R} 141 \mathrm{H}$ & $\mathrm{IL}$ \\
2 & $422 \mathrm{G}>\mathrm{A}$ & $\mathrm{R} 141 \mathrm{H}$ & $677 \mathrm{C}>\mathrm{G}$ & $\mathrm{T} 226 \mathrm{~S}$ & $\mathrm{ES}$ \\
3 & $422 \mathrm{G}>\mathrm{A}$ & $\mathrm{R} 141 \mathrm{H}$ & $647 \mathrm{~A}>\mathrm{T}$ & $\mathrm{N} 216 \mathrm{I}$ & $\mathrm{TR}$ \\
4 & $422 \mathrm{G}>\mathrm{A}$ & $\mathrm{R} 141 \mathrm{H}$ & $647 \mathrm{~A}>\mathrm{T}$ & $\mathrm{N} 216 \mathrm{I}$ & $\mathrm{TR}$ \\
5 & $357 \mathrm{C}>\mathrm{A}$ & $\mathrm{F} 119 \mathrm{~L}$ & $422 \mathrm{G}>\mathrm{A}$ & $\mathrm{R} 141 \mathrm{H}$ & $\mathrm{NL}$ \\
6 & $620 \mathrm{~T}>\mathrm{C}$ & $\mathrm{F} 206 \mathrm{~S}^{*}$ & $647 \mathrm{~A}>\mathrm{T}$ & $\mathrm{N} 216 \mathrm{I}$ & $\mathrm{ES}$ \\
7 & $278 \mathrm{~A}>\mathrm{C}$ & $\mathrm{E} 93 \mathrm{~A}^{* *}$ & $422 \mathrm{G}>\mathrm{A}$ & $\mathrm{R} 141 \mathrm{H}$ & $\mathrm{ES}$ \\
8 & $124 \mathrm{G}>\mathrm{A}$ & $\mathrm{G} 42 \mathrm{R}^{* *}$ & $640 \mathrm{G}>\mathrm{A}$ & $\mathrm{G} 214 \mathrm{~S}^{* *}$ & unknown \\
9 & $422 \mathrm{G}>\mathrm{A}$ & $\mathrm{R} 141 \mathrm{H}$ & $667 \mathrm{G}>\mathrm{A}$ & $\mathrm{D} 223 \mathrm{~N}^{* *}$ & $\mathrm{I}$ \\
10 & $385 \mathrm{G}>\mathrm{A}$ & $\mathrm{V} 129 \mathrm{M}$ & $422 \mathrm{G}>\mathrm{A}$ & $\mathrm{R} 141 \mathrm{H}$ & $\mathrm{I}$ \\
11 & $191 \mathrm{~A}>\mathrm{G}$ & $\mathrm{Y}^{*} 4 \mathrm{C}^{* *}$ & $191 \mathrm{~A}>\mathrm{G}$ & $\mathrm{Y} 64 \mathrm{C}^{* *}$ & $\mathrm{ES}$ \\
12 & $191 \mathrm{~A}>\mathrm{G}$ & $\mathrm{Y}^{*} \mathrm{C}^{* *}$ & $422 \mathrm{G}>\mathrm{A}$ & $\mathrm{R} 141 \mathrm{H}$ & $\mathrm{ES}$ \\
13 & $24 \mathrm{delC} \mathrm{C}^{*}$ & frameshift & $691 \mathrm{G}>\mathrm{A}$ & $\mathrm{V} 231 \mathrm{M}$ & unknown \\
14 & $95 \mathrm{TA}>\mathrm{GC}$ & L32R & $385 \mathrm{G}>\mathrm{A}$ & $\mathrm{V} 129 \mathrm{M}$ & $\mathrm{I}$ \\
\hline
\end{tabular}

The shaded boxes indicate mutations that were not included in the test series $\left({ }^{*}\right)$ or were not published before $\left(^{* *}\right)$.

Table 3 Mutations in MPI, ALG6, DPM1, ALG3 and MPDU1 detected by DHPLC

\begin{tabular}{|c|c|c|c|}
\hline \multirow[b]{2}{*}{ Gene } & \multirow[b]{2}{*}{ Exon } & \multicolumn{2}{|c|}{ Mutation } \\
\hline & & Base change & Amino acid change \\
\hline \multirow[t]{8}{*}{ MPI } & 3 & $152 \mathrm{~T}>\mathrm{C}$ & M51T \\
\hline & 3 & $166-167$ ins $C$ & frameshift \\
\hline & 3 & $304 C>T$ & S102L \\
\hline & 4 & $386 \mathrm{~A}>\mathrm{G}$ & Y129C* \\
\hline & 4 & $391 \mathrm{G}>\mathrm{A}$ & D131N \\
\hline & 4 & $413 \mathrm{~T}>\mathrm{C}$ & M138T \\
\hline & 4 & $457 \mathrm{G}>\mathrm{A}$ & R152Q \\
\hline & 8 & $1252 \mathrm{G}>\mathrm{A}$ & $\mathrm{R} 418 \mathrm{H}$ \\
\hline \multirow[t]{5}{*}{ ALG6 } & 3 & IVS $3+5 \mathrm{G}>\mathrm{A}$ & aberrant splicing \\
\hline & 8 & $680 \mathrm{G}>\mathrm{A}$ & G227E* \\
\hline & 10 & $911 \mathrm{~T}>\mathrm{C}$ & F304S \\
\hline & 11 & $998 \mathrm{C}>\mathrm{T}$ & A333V \\
\hline & 14 & $1432 \mathrm{~T}>\mathrm{C}$ & S478P \\
\hline \multirow[t]{3}{*}{ DPM1 } & 3 & $274 C>G$ & R92G \\
\hline & 4 & 331-343 del & frameshift \\
\hline & 8 & 628 delC & frameshift \\
\hline ALG3 & 2 & $211 \mathrm{~T}>\mathrm{C}$ & W71R* \\
\hline \multirow{4}{*}{ MPDU1 } & 1 & $2 \mathrm{~T}>\mathrm{C}$ & M1T \\
\hline & 3 & $218 \mathrm{G}>\mathrm{A}$ & G73E \\
\hline & 4 & $356 \mathrm{~T}>\mathrm{C}$ & L119P \\
\hline & 6 & 511 del C & frameshift \\
\hline
\end{tabular}

*These mutations have not been published before.

protocols. We have not experienced any false negative results until now. Of course, this does not imply that all possible mutations will be detected after careful comparison of the chromatograms with a wild type sample, and some experience with the interpretation is an asset.

The only disturbance in the analysis stems from the presence of polymorphisms in the scrutinized fragments. For instance, two frequent polymorphisms in intron 5 of PMM2 (IVS5+19 $\mathrm{C}>\mathrm{T}$ and IVS5+22 $\mathrm{T}>\mathrm{A}$ ) are detected by DHPLC using the primer sets and conditions, described in this study, and therefore complicate the analysis of exon

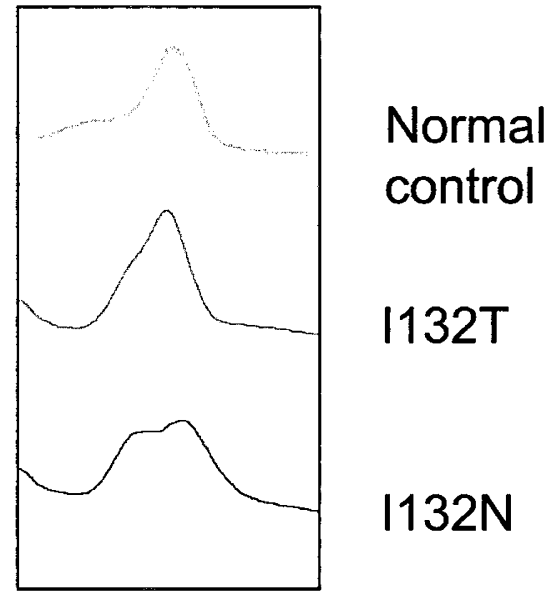

Figure 2 Comparison of the elution profile with the column temperature at $60^{\circ} \mathrm{C}$ of amplicons of exon 5, from a normal control and from patients, heterozygous for the $1132 \mathrm{~T}$ or $1132 \mathrm{~N}$ mutations respectively.

5. Because these polymorphisms are close to the splice site, they cannot be avoided by shuffling the primers without a loss of information. From a practical standpoint, because mutations in exon 5 are present on $60 \%$ of all mutant chromosomes, exon 5 has to be sequenced for most patients anyway. For MPI, new primers could be designed to avoid intronic polymorphisms.

We have been able to rapidly confirm the clinical diagnosis of CDG is several patients. This is of prime importance for the patients and families, and is a prerequisite for prenatal diagnosis. ${ }^{24}$

In conclusion, the DHPLC analysis was swift and the technique is sensitive. Hence, it must be equally applicable to candidate genes for unknown types of CDG.

\section{Acknowledgements}

This work was supported by the European Commission, contact no QLG1-CT2000-00047 (EUROGLYCAN) and by 'Fonds voor Wetenschappelijk Onderzoek - Vlaanderen', contract no G.0243.98. We thank the following doctors for their patient samples and clinical advice: Dr H Mandel, Dr D Quelhas, Dr M Topcu, Dr L Balogh, Dr J Christodoulou, Dr B De Martenville, Dr T De Koning, Dr L Dorland, Dr P Briones, Dr C Körner, Dr R Barone, Dr R Wevers and Dr J Jaeken.

\section{References}

1 Aebi M, Hennet T: Congenital disorders of glycosylation: genetic model systems lead the way. Trends Cell Biol 2001; 11: 136-141.

2 Jaeken J, Matthijs G: Congenital disorders of glycosylation. Annu Rev Genomics Hum Genet 2001; 2: 129-151.

3 Leonard J, Grunewald S, Clayton P: Diversity of congenital disorders of glycosylation. Lancet 2001; 357: 1382-1383.

4 de Lonlay P, Seta N, Barrot S et al: A broad spectrum of clinical presentations in congenital disorders of glycosylation I: a series of 26 cases. J Med Genet 2001; 38: 14-19. 
5 Erlandson A, Bjursell C, Stibler $\mathrm{H}$ et al: Scandinavian CDG-Ia patients: genotype/phenotype correlation and geographic origin of founder mutations. Hum Genet 2001; 108: 359-367.

6 Matthijs G, Schollen E, Bjursell C et al: Mutations in PMM2 that cause congenital disorders of glycosylation, type Ia (CDG-Ia). Hum Mutat 2000; 16: 386-394.

7 Grünewald S, Schollen E, Van Schaftingen E, Jaeken J, Matthijs G: High residual activity of PMM2 in patients' fibroblasts: possible pitfall in the diagnosis of CDG-Ia (phosphomannomutase deficiency). Am J Hum Genet 2001; 68: 347-354.

8 Imbach T, Burda P, Kuhnert P et al: A mutation in the human ortholog of the Saccharomyces cerevisiae ALG6 gene causes carbohydrate-deficient glycoprotein syndrome type-Ic. Proc Natl Acad Sci USA 1999; 96: 6982-6987.

9 Grünewald S, Imbach T, Huijben K et al: Clinical and biochemical characteristics of congenital disorder of glycosylation type Ic, the first recognized endoplasmic reticulum defect in N-glycan synthesis. Ann Neurol 2000; 47: 776-781.

10 Hanefeld F, Korner C, Holzbach-Eberle U, von Figura K: Congenital disorder of glycosylation-Ic: case report and genetic defect. Neuropediatrics 2000; 31: 60-62.

11 Jaeken J, Matthijs G, Saudubray JM et al: Phosphomannose isomerase deficiency: a carbohydrate-deficient glycoprotein syndrome with hepatic-intestinal presentation. Am J Hum Genet 1998; 62: $1535-1539$.

12 Niehues R, Hasilik M, Alton G et al: Carbohydrate-deficient glycoprotein syndrome type Ib. Phosphomannose isomerase deficiency and mannose therapy. J Clin Invest 1998; 101: 14141420.

13 Westphal V, Kjaergaard S, Davis JA et al: Genetic and metabolic analysis of the first adult with congenital disorder of glycosylation type Ib: long-term outcome and effects of mannose supplementation. Mol Genet Metab 2001; 73: 77-85.

14 Korner C, Knauer R, Stephani U et al: Carbohydrate deficient glycoprotein syndrome type IV: deficiency of dolichyl-P-Man: Man(5)GlcNAc(2)-PP-dolichyl mannosyltransferase. EMBO J 1999; 18: 6816-6822.
15 Imbach T, Schenk B, Schollen E et al: Deficiency of dolichol-phosphate-mannose synthase-1 causes congenital disorder of glycosylation type Ie. J Clin Invest 2000; 105(2): 233-239.

16 Kim S, Westphal V, Srikrishna G et al: Dolichol phosphate mannose synthase (DPM1) mutations define congenital disorder of glycosylation Ie (CDG-Ie). J Clin Invest 2000; 105: 191 - 198.

17 Kranz C, Denecke J, Lehrman MA et al: A mutation in the human MPDU1 gene causes congenital disorders of glycosylation type If (CDGIf). J Clin Invest 2001; 108: 1613-1619.

18 Schenk B, Imbach T, Frank CG et al: MPDU1 mutations underlie a novel human congenital disorder of glycosylation, designated If. J Clin Invest 2001; 108: 1687-1695.

19 Schollen E, Dorland L, de Koning TJ: Genomic organization of the human phosphomannose isomerase (MPI) gene and mutation analysis in patients with congenital disorders of glycosylation type Ib (CDG-Ib). Hum Mutat 2000; 16: 247-252.

20 Imbach T, Grünewald S, Schenk B et al: Multi-allelic origin of congenital disorder of glycosylation (CDG)-Ic. Hum Genet 2000; 106: $538-545$.

21 Xiao W, Oefner PJ: Denaturing high-performance liquid chromatography: A review. Hum Mutat 2001; 17: 439-474.

22 Matthijs G, Schollen E, Van Schaftingen E, Cassiman JJ, Jaeken J: Lack of homozygotes for the most frequent disease allele in carbohydrate-deficient glycoprotein syndrome type 1A. Am J Hum Genet 1998; 62: 542-550.

23 Eng C, Brody LC, Wagner TM et al: Interpreting epidemiological research: blinded comparison of methods used to estimate the prevalence of inherited mutations in BRCA1. J Med Genet 2001; 38: $824-833$.

24 Matthijs G, Schollen E, Cassiman JJ et al: Prenatal diagnosis in CDG1 families: beware of heterogeneity. Eur J Hum Genet 1998; 6: $99-104$. 